\title{
Iron-deficiency anemia. A study of risk factors among adult population of Quetta Valley
}

\author{
Khalid Mahmood ${ }^{1 *}$, Hasan Salman Siddiqi ${ }^{2}$, Ashif Sajjad $^{1}$, Sohail Shoukat ${ }^{3}$, Zahid Mehmood $^{1}$, \\ Amir Wasim ${ }^{4}$, Alia B. Munshi ${ }^{3}$ \\ ${ }^{1}$ Institute of Biochemistry, University of Baluchistan, Quetta, Pakistan; *Corresponding Author: khaliduniversity@yahoo.com \\ ${ }^{2}$ Department of Medicine, Sandeman Provincial Hospital, Quetta, Pakistan \\ ${ }^{3}$ Center for Environmental Studies, PCSIR Labs Complex, Karachi, Pakistan \\ ${ }^{4}$ Department of Chemistry, University of Baluchistan, Quetta, Pakistan
}

Received 8 February 2011; revised 5 March 2011; accepted 6 April 2011

\section{ABSTRACT}

Risk factors for iron deficiency anemia among the adult population of the Quetta valley have been investigated. Anemic adult patients, both males and females, who were admitted in the Sandeman Provincial Hospital, Quetta, were invited to participate in this study. After detailed history and examination, preliminary blood tests including full blood counts, platelets count, retics count, absolute blood values and blood film examination were done. A clinical diagnosis was made based upon the findings of history, examination and blood tests. In patients suspected to have iron deficiency anemia, serum iron studies (i.e. serum iron, Total iron binding capacity (TIBC) and serum ferritin) were done to confirm the diagnosis. Among the selected anemic patients, $60 \%$ were iron deficiency anemic, while $40 \%$ were non-iron deficiency anemic. Iron deficiency anemia was more common among females than males, as $70 \%$ patients were female and $30 \%$ were male. The risk factors were found to be pregnancy ( $40 \%)$, nutritional inadequacy $(17 \%)$, menorrhagia (9\%), hemorrhoids $(9 \%)$, hook worms $(8 \%)$, hematuria $(2 \%)$ and blood loss due to various gastro-intestinal pathologies (15\%).

Keywords: Anemia; Iron Deficiency; Risk Factors; Quetta Valley

\section{INTRODUCTION}

Iron deficiency anemia (IDA) is the third and the final stage of iron deficiency which is said to be present when signs of iron deficiency are combined with a lowering of hemoglobin to a level below minus two standard devia- tions of the distribution of hemoglobin in normal subjects of the same age and sex and living at the same altitude. Although this concept is purely statistical, it is much used since internationally iron deficiency is the most common cause of anemia and hemoglobin is easy to measure [1]. Iron deficiency anemia occurs when the dietary intake or absorption of iron is insufficient, and hemoglobin, which contains iron, cannot be formed [2]. It is also a major public health problem throughout the globe especially in the developing countries. Infants, young children, menstruating women and in particular pregnant women are most frequently affected [3].

The iron deficiency often coexists with other conditions such as malnutrition, vitamin A deficiency, folate deficiency and infections. In the tropical regions, parasitic infestations and hemoglobinopathies are also a common cause of anemia. The conditions mentioned might contribute to the development of iron deficiency or they present difficulties in the laboratory diagnosis of iron deficiency [4,5]. In Pakistan, like other developing countries, we are facing the major problem of high population growth. Resources are limited which badly affect the socio-economic development of the country as a whole. Limited health care, poor hygiene and sanitation and low literacy rate are the main problems leading to various nutritional deficiencies including iron deficiency. Iron deficiency is a major health problem for health professionals and a challenge for policy makers in Pakistan [6]. It is a very common nutritional deficiency and a serious hematological problem in pregnancy. It is a major contributing factor to maternal and fetal morbidity and mortality [5]. In Pakistan various studies have been performed on different segments of the population covering many aspects of this important public health problem [7-14].

The aim of our study is to determine the risk factors for IDA among the adult population of Quetta valley. A clear understanding of risk factors in the population will 
help to plan for more effective strategies to control the nutritional deficiency and other causes.

\section{METHODOLOGY}

Anemic adult patients, both males and females, who were admitted in the Sandeman Provincial Hospital, Quetta, were invited to participate in this study. The Sandeman Provincial Hospital, Quetta is the largest Hospital for the population, most popular in low socio-economic families. Quarter a million of Afghan refugees living in the suburbs of the Quetta valley for years also use this hospital. The hospital serves more than $80 \%$ of the population of the valley, therefore selected for study.

The study included adults whose hemoglobin level was less than $12 \mathrm{~g} / \mathrm{dl}$ for males and less then $11 \mathrm{~g} / \mathrm{dl}$ for females. We excluded those patients who had donated blood or had received blood transfusion during the last three months, patients with recent documented acute blood loss, patients receiving iron supplements, patients with congenital heart and lung problems, patients with acute or chronic infections e.g. pneumonia, typhoid, tuberculosis etc., diagnosed cases of hematological malignancies and those taken recently high doses of broad spectrum antibiotics. Detailed clinical histories were recorded in each case and the symptoms suggestive of anemia in general and of iron deficiency anemia in particular were carefully noted. Relevant questions were asked to get an indication about the cause of the symptoms. A thorough physical examination was done and the positive findings were collected. Signs of anemia, especially iron deficiency anemia, were particularly looked for. Any sign giving a clue about the underlying pathology was carefully observed and noted. The following laboratory investigations were performed in duplicate. Hemoglobin concentration, Red cell indices: (PCV) Packed cell volume, (MCV) Mean Corpuscular Volume, (MCH) Mean Corpuscular Hemoglobin, (MCHC) Mean Corpuscular Hemoglobin Concentration, Peripheral blood film, Erythrocyte sedimentation rate (ESR), Reticulocyte count, Total and differential leukocyte count, Platelet count, Serum Ferritin (SF), Serum Iron (SI), Serum total iron binding capacity(TIBC), Bone marrow staining for iron stores, Blood urea, Urine analysis, Stool detailed report (including stool for occult blood), Abdominal ultrasound, Upper gastrointestinal endoscopy, Proctoscopy and lower gastrointestinal endoscopy and Barium studies of the gastrointestinal tract.

\section{Equipment}

Cell analyzer MEDONIC CA 530 (Medonic, Sweden) was used for determining hemoglobin concentration, red cell indices (packed cell volume, mean corpuscular hemoglobin and mean corpuscular hemoglobin concentra- tion), total leukocyte count, differential leukocyte count and platelet count. The erythrocyte sedimentation rate (ESR) was done by Wintrobe tube made in Germany. Blood urea was analyzed on Micro lab 200 (MERCK) made in Italy. For serum iron, Beckman kit run on Synchron CX system was used. Serum ferritin was run on Immulite manufactured by Euro/DPC, UK IBCT kit Beckman Coulter made in USA was used for measuring serum TIBC.

The blood hemoglobin concentration was done in all cases as a screening test for anemia. All patients with hemoglobin less then $12 \mathrm{~g} / \mathrm{dl}$ in males and less then 11 $\mathrm{g} / \mathrm{dl}$ in the females were labeled as "anemic" and were included in this study. The "anemic" patients were then subjected to red cell indices (PCV MCV MCH \& MCHC) and peripheral blood film. Those with red cell indices decreased below the normal levels and showing a microcytic hypo chromic picture on peripheral blood film were labeled as "Iron deficient anemic". On the other hand, the patients whose red cell indices were in the normal range or above the normal range and the peripheral film was not in favor of iron deficiency were labeled "non-iron deficient anemic" and were not considered for further investigations. Iron deficiency state was confirmed in patients labeled as "iron deficient anemic" by the estimation of serum ferritin or staining of the bone marrow for iron stores. These patients were then further investigated in order to find a cause for the iron deficiency anemia.

\section{RESULTS}

In $60 \%$ patients, the red cell indices were below the normal ranges and the peripheral blood film showed hypo chromic microcytic features with anisocytosis and poikilocytosis seen in some films. These $60 \%$ patients were labeled as "iron deficient anemic". This was later confirmed by bone marrow staining, which showed absent iron stores in all 60\% patients. Serum Ferritin and Serum total iron binding capacity (TIBC) proved useful for confirming iron deficiency state as well as for differentiating IDA from other "Microctytic anemic states" like Thalassemia Minor, anemia of chronic disease and Sideroblastic anemia. Serum Ferritin is decreased in IDA; normal in Thalassemia Minor while it is increased in anemia of chronic disease and Sideroblastic anemia. On the other hand, TIBC is increased in IDA; normal in Thalassemia minor while it is decreased in anemia of chronic disease and Sideroblastic anemia. In these 60\% patients labeled as "iron deficient anemic", Serum ferritin was found to be in the range 3 - $10 \mu \mathrm{g} / \mathrm{l}$ (Normal range: 12 - $302 \mu \mathrm{g} / \mathrm{l}$ ) while TIBC was in the range of 350 $400 \mu \mathrm{g} / \mathrm{dl}$ in some cases and $>400 \mu \mathrm{g} / \mathrm{dl}$ in most of the cases (Normal range: 300 - $350 \mu \mathrm{g} / \mathrm{dl}$ ). These results thus 
excluded the above mentioned conditions which present a microcytic picture on Peripheral smear. Iron deficiency anaemia was much more common among females than males as (70\%) were females and only (30\%) were males. It was found to be common in the age group 26 to 55 years of age in both the sexes. It was mostly a problem of the poor socio-economic class as (75\%) belonged to the lower socio-economic class who were malnourished for months, (20\%) belonged to the middle class families and (5\%) were members of upper class families. Among the investigations the most important one was the hemoglobin level. In $90 \%$ of the iron deficient anemic patients, it was found to be in the range of $4-9 \mathrm{~g} / \mathrm{dl}$ (Table 1). Investigations performed in order to determine the cause of iron deficiency anemia in these patients included abdominal ultrasonography, protoscopy and lower gastrointestinal endoscopy, upper gastrointestinal endoscopy, stool examination for occult blood, ova and parasites, barium studies of the gastrointestinal tract and urine analysis (Table 2).

\section{DISCUSSION}

The analysis made is meant to address the deficiencies of women living in deprived conditions particularly while having to look after the family too. Also to disseminate the information to scientific community to be careful in other regions where such type of life style may exist. Studies also verify the consequences of nutritional deficiencies complicating the miseries of poor people living under miserable conditions. Iron deficiency ane- mia was the most common type of anemia among the anemic patients admitted in Sandeman Provincial Hospital, Quetta, as 60\% of the anemic patients were iron deficient while the rest $40 \%$ had anemia due to other causes. This is in accordance with studies carried out in various other regions of Pakistan [13-15].

In this study, $70 \%$ of the iron deficient anemic patients were females - thus IDA was found to be much more common among females than males especially in the child bearing age. At puberty, menstruation increases the risk of iron deficiency. Pregnancy markedly increases iron requirement in the second and third trimesters due to high growth rates of placenta and fetus and the expansion of maternal red cell mass. Thus anemia affects 50\% $70 \%$ of the pregnant women in the developing countries. This was highlighted by a study conducted in underprivileged class of Karachi [16]. They get a diet of inferior quality as compared to that of males due to social customs. Most of the pregnant women do not get iron supplementation during pregnancy and lactation. Hence increased demands and decreased supply multiply the magnitude of the problem due to which IDA is so commonly found among women of childbearing age. In this study IDA was found to be more common in persons aged 26 - 55 years while it was less common in young adults and in the elderly. This trend was the same in the males as well as in the females. The cause in the females is obvious because, as described above, females are prone to IDA in the reproductive age. However, it is remarkable to find males as sufferers in the same age group.

Table 1. Investigations showing the diagnosis of iron deficiency anemia.

\begin{tabular}{|c|c|c|c|c|c|c|c|}
\hline \multicolumn{8}{|c|}{ Results of hemoglobin (Hb), erythrocyte sedimentation rate (ESR) and packed cell volume (PCV) in IDA patients. } \\
\hline Investigation & Normal value & \multicolumn{3}{|c|}{ Range of result } & \multicolumn{3}{|c|}{$\%$ of patients } \\
\hline $\mathrm{Hb} g / \mathrm{dl}$ & Male: 13 - 18, Female: 11.5 - 16.5 & $4-7$ & $7-9$ & $9-12$ & 20 & 70 & 10 \\
\hline ESR mm/1st hr & Male: 0 - 10, Female: 3 - 15 & $50-80$ & $60-70$ & $20-28$ & 10 & 60 & 30 \\
\hline PCV \% & Male: 40 - 54, Female: 37 - 47 & $20-28$ & $28-32$ & $>32$ & 33 & 55 & 12 \\
\hline \multicolumn{8}{|c|}{$\begin{array}{l}\text { Results of red cell indices: mean corpuscular volume (MCV), mean corpuscular hemoglobin (MCH) and } \\
\text { mean corpuscular hemoglobin concentration (MCHC) in IDA patients. }\end{array}$} \\
\hline Investigation & Normal value & \multicolumn{3}{|c|}{ Range of result } & \multicolumn{3}{|c|}{$\%$ of patients } \\
\hline MCV (fL) & $80-100$ & $60-70$ & & $70-80$ & 51 & & 49 \\
\hline MCH (pg/cell) & $26-34$ & $20-23$ & & $23-26$ & 45 & & 55 \\
\hline MCHC (g/dl) & $32-36$ & $20-25$ & & $25-29$ & 40 & & 60 \\
\hline \multicolumn{8}{|c|}{ Results of serum iron studies: serum ferritin (SF), serum iron SI) and total iron binding capacity (TIBC) in IDA patients. } \\
\hline Investigation & Normal value & \multicolumn{3}{|c|}{ Range of result } & \multicolumn{3}{|c|}{$\%$ of patients } \\
\hline $\mathrm{SF}(\mu \mathrm{g} / \mathrm{l})$ & $12-302$ & $3-6$ & & $6-10$ & 33 & & 67 \\
\hline SI $(\mu \mathrm{g} / \mathrm{dl})$ & $50-150$ & $2-6$ & & $6-11$ & 30 & & 70 \\
\hline TIBC ( $\mu \mathrm{g} / \mathrm{dl})$ & $300-360$ & $350-400$ & & $>400$ & 25 & & 75 \\
\hline
\end{tabular}


Table 2. Investigations showing the cause of iron deficiency anemia.

\begin{tabular}{|c|c|c|c|}
\hline S. No & Investigations & Findings & Results \\
\hline \multirow{3}{*}{1.} & \multirow{3}{*}{$\begin{array}{l}\text { Abdominal } \\
\text { ultrasonography }\end{array}$} & Pregnancy & 43 \\
\hline & & Splenomegaly & 03 \\
\hline & & Normal & 54 \\
\hline \multirow{3}{*}{2.} & \multirow{3}{*}{ Stool } & Occult blood & 25 \\
\hline & & Ova of hookworm & 8 \\
\hline & & Normal & 67 \\
\hline \multirow{3}{*}{3.} & \multirow{3}{*}{$\begin{array}{l}\text { Upper gastrointestinal } \\
\text { endoscopy }\end{array}$} & Gastric erosions & 8 \\
\hline & & Peptic ulcer & 7 \\
\hline & & Normal & 85 \\
\hline \multirow{2}{*}{4.} & \multirow{2}{*}{$\begin{array}{l}\text { Barium study of } \\
\text { gastrointestinal tract }\end{array}$} & Peptic ulcer & 7 \\
\hline & & Normal & 93 \\
\hline \multirow{2}{*}{5.} & \multirow{2}{*}{ Proctoscopy } & Hemorrhoids & 8 \\
\hline & & Normal & 92 \\
\hline
\end{tabular}

It is probably due to poverty and poor sanitation. They work hard as laborers and do not get adequate diet, thus develop several nutritional deficiencies including iron deficiency. Poor sanitation makes them vulnerable to parasitic infestations especially hookworm infection. The fact that $75 \%$ of the iron deficient cases in this study belonged to the poor class supports this hypothesis; $20 \%$ were middle class people while only $5 \%$ were socially well off to be included in the upper class.

This study found that the same etiology has persisted over the years, which was mentioned in other studies conducted earlier. The most common risk factor was pregnancy found in $43 \%$ cases. In pregnancy, IDA has been observed very frequently in a number of studies [5, 17-21].

In this study, nutritional inadequacy was found to be the second most common cause of iron deficiency anemia. These patients did not have any accompanying disease but belonged to very poor families in which mostly there was a single bread earner for a large number of dependent family members. Gastric erosions were found in $8 \%$ patients, all of them had taken some form of non steroidal anti-inflammatory drugs without consultation of the doctor, either on empty stomach or in improper dosage. The trend of self-medication especially for pain has increased leading to increased incidence of epigastric discomfort and gastric erosions on prolonged use that ultimately causes iron deficiency anemia. 8\% patients were found to be infested by hookworm infection, which is one of the commonest causes of IDA worldwide.

Among the investigations, the $\mathrm{Hb} \%$ was of course the basic and the most important investigation, which con- firmed the clinical suspicion of anemia. In order to find out the type of anemia, this study concluded that peripheral smear was the most useful investigation. The morphological picture was then verified by the absolute values. The diagnosis of iron deficiency anemia was confirmed by serum ferritin, serum iron, total iron binding capacity and bone marrow staining for iron stores. Serum ferritin proved to be a very useful investigation in the diagnosis of IDA. Serum ferritin is considered to be the "Gold standard" for the diagnosis of IDA in pregnancy [22-25]. Similarly bone marrow staining for iron stores, although painful for the patient, was found to play a decisive role in the diagnosis of IDA. The absence of iron stores in the bone marrow has been one of the most definitive tests for differentiating IDA from other microcytic states for a long time [26-28]. In order to determine the cause of IDA, our study found that investigations of the upper as well as the lower gastrointestinal tract are very useful. In many cases, loss of blood due to some gastrointestinal pathology was the underlying cause of IDA while in some cases in which the primary cause of IDA was other than gastrointestinal pathology, a mild to moderate amount of blood loss from the GIT was a contributory factor that increased the severity of IDA e.g. in certain pregnant females. Therefore, thorough GIT investigations must be done in all cases of anemia even if one cause seems to be obvious. In addition to dietary insufficiency, malabsorption, chronic blood loss, diversion of iron to fetal erythropoiesis during pregnancy, intravascular haemolysis and haemoglobinuria or other forms of chronic blood loss should also be carefully considered. Awareness and the supplement to the needy is playing vital role to have healthy population especially children and women, living in stressed conditions. The right time investigation of the disease and deficiencies will surely provide opportunities of better family care.

\section{CONCLUSION}

Iron deficiency anemia is found to be a common problem in patients admitted to the Sandeman Provincial Hospital, Quetta. The majority of the iron deficient anemic patients are females; thus it is concluded that iron deficiency anemia is much more common among fe-

Table 3. Risk factors of iron deficiency anemia.

\begin{tabular}{clc}
\hline S. No. & Risk factor & Result (\%) \\
\hline 1 & Pregnancy & 43 \\
2 & Nutritional inadequacy & 15 \\
3 & Various gastro intestinal pathologies & 15 \\
4 & Menorrhagia & 9 \\
5 & Hemorrhoids & 8 \\
6 & Hook worms & 8 \\
7 & Hematuria & 2 \\
\hline
\end{tabular}


males than males in the Quetta valley especially in the child bearing age. The important risk factors include multiple pregnancies, nutritional inadequacy and various gastro-intestinal pathologies (Table 3). Iron deficiency anemia is mostly a problem of the poor class as the majority of the patients had a very low socioeconomic status. It can thus be concluded from all these studies that iron deficiency anemia (IDA) is the most common type of anemia among the anemic population of Quetta valley.

\section{REFERENCES}

[1] Hallberg, L., Bengtsson, C., Lapidus, L., Lindstedt, G., Lundberg, P.A. and Hulten, L. (1993) Screening for deficiency. British Journal of Haematology, 85, 787-798. doi:10.1111/j.1365-2141.1993.tb03225.x

[2] Brady, P.G. (2007) Iron deficiency anemia: A call for aggressive diagnostic evaluation. Southern Medical Journal, 100, 966-967. doi:10.1097/SMJ.0b013e3181520699

[3] Hercberg, S. and Galan, P. (1992) Nutritional anemias. Baillier's Clinical Hematology, 5, 143-168.

[4] Olivares, M., Walter, T., Hertrampf, E. and Pizarro, F. (1999) Anemia and iron deficiency in children. British Medical Bulletin, 55, 534-543. doi:10.1258/0007142991902600

[5] Paracha, P.L., Hameed, A., Simon, J., Jamil, A. and Nawab, G. (1997) Prevalence of Anemia in semi-urban areas of Peshawar, Pakistan. A challenge for health professionals and policy makers. Journal of Pakistan Medical Association, 47, 49-53.

[6] Dreyfuss, M.L., Stoltzfus, R.J., Shrestha, J.B., et al. (2000) Hookworms, malaria and vitamin A deficiency contribute to anemia and iron deficiency among pregnant women in the plains of Nepal. Journal of Nutrition, 130, 2527-2536.

[7] Abbasi, P.A. and Shah, Q. (1998) Comparison of different modes of correction of iron deficiency anaemia in pregnancy. Medical Channel, 4, 29-33.

[8] Hayat, T.K. (1997) Iron deficiency anemia during pregnancy. Journal of the College of Physicians and Surgeons-Pakistan, 7, 11-13.

[9] Syed, T.S. (1998) Iron deficiency anaemia in pregnant women attending the antenatal clinic. Medical Channel, $\mathbf{3}$, 49-51.

[10] Akhter, M.S., Akhter, M.W., Tajammul, A., Malik, M., Nighat, U. and Akhtar, N.S. (1997) Profile of anaemic patients attending a tertiary care hospital in Pakistan, study of 650 cases. Medical Channel, 3, 9-12.

[11] Khan, I.A. (1988) A study of anemia in NWFP. Khyber Medical Journal, 6, 34-40.

[12] Hashmi, J.A., Afroz, N., Nisa, Q., Malik, F., Saeed, M. and Choudhry, A.S. (1973) Study of anaemia in pregnancy at the Jinnah postgraduate Medical Center, Karachi. Journal of Pakistan Medical Association, 12, 23-33.

[13] Heiner, J.D., Siddiqui, A.R. and Aziz, M.A. (1972) Anaemia in pregnancy in an urban population of West
Pakistan. Pakistan Journal of Medical Research, 11, 2635.

[14] Baig, L., Thaver, I., Haq, I.U. and Iqbal, R. (1996) Risk factors associated with anaemia in children six months to five years of age residing in a squatter settlement of Karachi. Pakistan Journal of Medical Research, 35, 176-178.

[15] James, D.C. (2005) Diagnosis and management of irondeficiency anaemia. Best Practice \& Research Clinical Haematology, 18, 319-332. doi:10.1016/j.beha.2004.08.022

[16] Molla, A., Khurshid, M. and Molla, A.M. (1992) Prevalence of iron deficiency anaemia in children of the urban slums of Karachi. Journal of Pakistan Medical Association, 42, 118-121.

[17] Karim, S.A., Khurshid, M., Memon, A.M. and Jafarey, S.N. (1994) Anemia in pregnancy-Its cause in the under privileged class of Karachi. Journal of Pakistan Medical Association, 44, 90-91.

[18] Agha, F. and Khan, R.A. (1989) Ferritin level in professional blood donors. Journal of Pakistan Medical Association, 39, 124-126.

[19] Scholl, T.O. and Hediger, M.L. (1994) Anaemia and iron deficiency anaemia: Compilation of data on pregnancy outcome. American Journal of Clinical Nutrition, 59, 492S-501S.

[20] Beard, J.L. (1994) Iron deficiency: Assessment during pregnancy and its importance in pregnant adolescents. American Journal of Clinical Nutrition, 59, 502S-510S.

[21] Singh, K., Fong, Y.F. and Arulkumaran, S. (1998) The role of prophylactic iron supplementation in pregnancy. International Journal of Food Sciences and Nutrition, 49, 383-389.

[22] Scholl, T.O., Hediger, M.L., Fischer, R.L. and Shearer, J.W. (1992) Anaemia vs iron deficiency: Increased risk pre term delivery in a prospective study. American Journal of Clinical Nutrition, 55, 985-988.

[23] Celghorn, G. (1999) Iron deficiency and cognitive development. Medical Channel. In: Current Trends in Gastroenterology and Nutrition, 6th Congress of the Asian PanPac Soc of Paed GE \& Nutrition, Singapore City.

[24] Puolakka, J., Janne, O., Pakarinen, A., Jarvinen, P.A. and Viko, R. (1980) Serum ferritin as a measure of iron stores during and after normal pregnancy with and without iron supplements. Acta Obstetricia et Gynecologica Scandinavica, 95, 43-51. doi:10.3109/00016348009156379

[25] Puolakka, J., Janne, O., Pakarinen, A. and Vikho, R. (1980) Serum ferritin in the diagnosis of anaemia during pregnancy. Acta Obstetricia et Gynecologica Scandinavica, 95, 57-63. doi:10.3109/00016348009156381

[26] Kumar, P. and Clark, M. (1998) Hematological disease. 4th Edition, W.B. Saunders, Philadelphia, 353-414.

[27] Cotran, R.S., Kumar, V. and Collins, T. (1999) Red cells and bleeding disorders: Robbin's pathological basis of disease. 6th Edition, W.B. Sauders, Philadelphia, 601- 643.

[28] Wulfhekel, U. and Dullmann, J. (1990) The diagnostic value of bone marrow iron. Folia Haematologica, 117, 419-434. 